Australian Journal of

Crop Science

AJCS

AJCS 14(02):371-381 (2020)

ISSN:1835-2707

doi: 10.21475/ajcs.20.14.02.p2557

\title{
Growth, biomass distribution, gas exchange and chlorophyll fluorescence in cowpea (Vigna unguiculata (L.) Walp.) under drought conditions
}

\author{
Carlos Cardona-Ayala*, Carlos Cardona-Villadiego, Carlos Peñate-Pacheco, Hermes Araméndiz-Tatis, Miguel \\ M. Espitia-Camacho
}

\begin{abstract}
Grupo de investigación Cultivos Tropicales de Clima Cálido [Research Group on Tropical Crops of Warm Climates], Faculty of Agricultural Sciences, Universidad de Córdoba, Cr. 6 No. 77-305, Montería, Córdoba, Colombia
\end{abstract}

\section{*Corresponding author: ccardonaayala@yahoo.com}

\begin{abstract}
Drought modifies plant development and generates losses in agricultural production. The aim of this study was to analyze the growth, biomass distribution, gas exchange, and chlorophyll fluorescence in nine cowpea (Vigna unguiculata) genotypes under drought conditions in the greenhouse condition. A completely randomized experimental design with four replicates was used. The following genotypes (treatments) of LC-006-016, LC-029-016, LC-036-016, LC-021-016, LC-005-016, LC-009-016, LC-014-016, LC-002-016, and Caupicor-50 (control) were evaluated with irrigation for 21 days (after sowing) and 38 days of drought (DD) for a total duration of 59 days. In a simultaneous experiment, other plants of the same genotypes were irrigated for 59 days after sowing (DAS) with replacement of evapotranspirated water every three days. Measures of plant height and number of leaves were taken every four days, biomass at 59 days, gas exchange every seven days and chlorophyll fluorescence at 17, 21 and 38 DD. Moisture losses were quantified by recording the loss of soil weight every three days. The results showed that plant height reached $72.2 \%$ lower in plants under drought, while the vegetative biomass decreased by $76.3 \%$. The photosynthesis, stomatal conductance, and transpiration were decreased $64.6 \%, 93.1 \%$, and $86.9 \%$ under drought, respectively. Furthermore, intrinsic water use efficiency $\left(A / g_{s}\right)$ was increased almost six times. However, it was decreased when drought progressed towards the soil water content loss more than 0.0827 g.g $\mathrm{g}^{-1}$. The quantum yield of photosynthesis (DPSII) was decreased $28.4 \%, 40.3 \%$ and $43.5 \%$ at 17,21 and 38 DD, respectively, under drought condition. The principal component analysis (PCA) suggests that the genotypes with higher $A / g_{s}$ and those with higher biomass production show greater resistance to drought.
\end{abstract}

Keywords: Photoprotection; Photosynthesis; Soil moisture; Stomatal conductance; Transpiration.

Introduction

Cowpea (Vigna unguiculata (L.) Walp.) is one of the most important crops worldwide as it is part of the diet of millions of poor people in less developed tropical countries. Farmer families that cultivate this legume obtain a good income from the produced seed, especially the cream-colored cultivar with a black hilum (Olajide and Ilori, 2017). The seeds and fresh pods of this legume provide nutritional benefits, as they are rich in proteins, minerals (iron and zinc) and vitamins. Also, this crop improves soil fertility through nitrogen fixation (Ovalesha et al., 2017).

Among the technological limitations that cowpea cultivation encounters, the lack of cultivars with high grain yield and nutritional quality is critical. Their performance in environments where drought stress limits the survival of cultivars and production is also very important. Erratic rainfall due to climate change reduces cowpea grain yield (Olajide and Ilori, 2017) to such an extent that drought has caused relative reductions in yield from 0.38 up to $0.69,57 \%$ in grain yield per plant, $49 \%$ in the number of pods per plant, and $32 \%$ of the number of seeds per pod (Cardona-Ayala et al., 2013).

The adverse effects of water deficit are reflected in mineral nutrition and metabolism and lead to decreased leaf area, altered assimilates partition between organs (Merwad et al., 2018), decrease in plant height and in number of leaves per plant (Fahad et al., 2017). Furthermore, it also decreases the photosynthesis $(A)$, transpiration $(E)$, and stomatal conductance $\left(g_{s}\right)$ and increase the intrinsic water use efficiency $\left(A / g_{s}\right)$ (Singh and Reddy, 2011).

The $A / g_{s}$ has been recognized as a measure of the carbon gain per water unit lost and is inversely proportional to the ratio between intercellular and environmental $\mathrm{CO}_{2}$ concentrations $\left(C_{i} / C_{a}\right)$. Therefore, higher water use efficiency and higher photosynthetic rate, together with a greater mobilization of 
photoassimilates towards the harvest organs can improve crop yield under water stress (Singh and Reddy, 2011).

Chlorophyll a fluorescence is a technique that has been used to detect the effects of various abiotic stresses, such as salinity and drought. A correlation has been reported between the quantum performance of the photosystem II (DPSII) and the quantum yield of $\mathrm{CO}_{2}$. So, ФPSII can be used to select plants with different photosynthetic capacities in stressful environments (Surabhi et al., 2009). The technique is based on the fact that the energy of the photons captured by the antenna complexes in the reaction centers of the photosystem II (PSII) located in the photosynthetic apparatus of plants, following three simultaneous processes. (a) the photon is transferred to other molecules to drive the photochemical process to form carbohydrates, (b) it dissipates as heat, and (c) it is re-emitted as low energy light or chlorophyll fluorescence, i.e., at wavelengths longer than those captured. However, the increase in the efficiency of one of the processes makes the other two decrease as well (Delgadillo et al., 2017). Stressors affect the role of PSII and modify the emission of fluorescence, which can reveal response mechanisms of plants and allows analyzing and quantifying the effects of stress.

Plant strategies to survive water stress can be categorized into three types: escape drought, avoidance of drought (water conservation), and drought tolerance. The first is the shortening of the life cycle (Agbicodo et al., 2009), which evades the dry season within a year and completes its life cycle in the rainy season. The second is related to the maintenance of the hydric state of the plant with negative consequences for photosynthesis. Plants avoid drought by showing morphological and physiological adjustments, such as the reduction of stomatal conductance and leaf area (Singh and Reddy, 2011), increase foliar wax and leaf or leaflet curling to minimize evaporation (Hall, 2012). The third involves mechanisms that facilitate (a) the maintenance of open stomata through osmotic adjustment that involves the synthesis and accumulation of organic solutes in the cytoplasm and the entry of inorganic solutes into the vacuoles (Blum, 2016), (b) structural modifications of cell walls and membranes (Jin et al., 2016), and (c) increase in root density and depth (Sicher et al., 2012).

Subsistence agriculture in semi-arid regions uses species with the escape strategy. However, due to the irregularity of rainfall in these regions, it is common to experience long periods without rain during the crop cycle. In this case, plant survival and crop yield will depend on strategies such as water conservation or tolerance to drought (Freitas et al., 2017).

Typically, new cultivars are obtained by selection during harvest and according to their components in specific environments without evaluating the effects of drought in different growth and development stages. Hence, it is necessary to complement the breeding strategy with the evaluation of new cultivars under prolonged drought conditions (Olajide and Ilori, 2017). In this way, phenotypic plasticity expressions of features associated with survival and drought resistance that could be used to select cultivars can be identified. Nonetheless, differences among genotypes in their ability to survive imposed drought conditions have been reported (Cardona-Ayala et al., 2013, Singh and Reddy, 2011).
Accordingly, the aim of this study was to analyze the effect of drought on the growth, biomass distribution, gas exchange, and chlorophyll fluorescence of nine cowpea genotypes under drought conditions to contribute to the selection of genotypes adapted to drought.

\section{Results and discussion}

\section{Plant growth and biomass distribution}

The plant height and the number of leaves did not show significant differences between genotypes under drought, while under irrigation, Caupicor-50, presented greater height (Table 1). In 38 drought days (DD), plant height increased 5.6 $\mathrm{cm}$, i.e., equivalent to an average increase of $0.14 \mathrm{~cm}$ per day (Table 2). In well-hydrated plants, the increase was $50.6 \mathrm{~cm}$, equal to an average increase of $1.30 \mathrm{~cm}$ per day, which is 9.3 times higher, compared to drought-stressed plants. This significant difference in height is attributable to the effect of drought. The change of growth habit to indeterminate was only expressed in well-hydrated plants.

From the 14th DD, in the pre-flowering stage, plant height was significantly lower, compared to plants with irrigation (Table 2 ). The drought slowed plant growth, and from day 21 of drought, the plants exhausted all the available water around 1.5 Mpa. Therefore, to survive, they had to resist superior humidity tensions, as has been reported by Cardona-Ayala et al. (2013).

At the end of the drought period, eight genotypes could maintain between 6 and 7 leaves, differing statistically from LC-006-016 (Table 1), representing only $54.5 \%$ of those produced under irrigation. Similar results were observed in Egypt with the cowpea cultivar Doki 331 (Merwad et al., 2018). Under drought conditions, genotypes developed fewer leaves because of the low water availability for photosynthetic processes. This decrease is related to low stomatal conductance and an increase in intrinsic water use efficiency (Singh and Reddy, 2011).

On the other hand, there were no significant differences between genotypes in vegetative biomass (stems and leaves), total aerial biomass (stems, leaves and reproductive structures), and root biomass (Table 3). The drought affected all genotypes similarly. However, only four genotypes formed flowers: Caupicor-50, LC-006-016, LC-002-016, and LC-014-016, and of these, only Caupicor-50 and LC-006-016 could develop pods with small size and weight $(<0.8 \mathrm{~g})$. This shows an adaptive feature aimed at shortening the biological cycle (escape) to form seeds, meanwhile the rest remained in a vegetative phase, probably avoiding drought. This adaptation could be useful when favorable soil moisture conditions occur to ensure the formation of seeds and with this, the survival of individuals. This result confirms that the reproductive phase is the most affected under drought conditions as has been shown by Ishiyaku and Aliyu (2013), and Cardona-Ayala et al. (2013).

\section{Gas exchange}

The analysis of variance of gas exchange parameters, including net photosynthesis $(A)$, stomatal conductance $\left(g_{s}\right)$, transpiration $(E)$, intrinsic water use efficiency $\left(A / g_{s}\right)$ and water 
use efficiency $(A / E)$, did not show a significant variation among cultivars in any of the nine readings conducted every four days from day 21 after sowing in well-irrigated plants. Only $A / E$ showed significant under irrigation condition (Table 4).

After 21 days without water supply, the water content of the substrate was reduced from $9.03 \%$ to $0.76 \%$, which indicates that the soil moisture tension was close to $-1.5 \mathrm{MPa}$. In this condition, photosynthesis, stomatal conductance, and transpiration were decreased $64.6 \%, 93.1 \%$, and $86.9 \%$, respectively, compared to well-hydrated plants (Table 4). Additionally, the increase in intrinsic water use efficiency $\left(A / g_{s}\right)$ was almost six times higher, and the water use efficiency $(A / E)$ was increased almost three times. When plants close their stomata, water loss is reduced considerably in detriment of carbon dioxide uptake. The progressive stomatal closure due to the increasing soil moisture deficit represents an advantage for this isohydric species (Tardieu and Simonneau, 1998), whose stomatal control system prevents the water potential in the xylematic tissue from falling below a critical threshold that would lead to turgor loss or embolism (Franks et al., 2007).

The decrease in photosynthesis $(A)$ with loss of soil water content during the drought period was progressive, which was explained by a second-degree polynomial model (Fig. 1 A). According to this estimated equation, photosynthesis decreased linearly at a rate of $77.53 \mu \mathrm{mol} \mathrm{CO}_{2} \mathrm{~m}^{-2} \mathrm{~s}^{-1}$ for each g. $\mathrm{g}^{-1}$ of soil moisture loss, with a linearity deviation of -554.4 $\mu \mathrm{mol} \mathrm{CO}_{2} \mathrm{~m}^{-2} \cdot \mathrm{s}^{-1}$.

Simultaneously, the stomatal conductance $\left(g_{s}\right)$ was decreased exponentially (Fig. $1 \mathrm{~B}$ ) and reached values of zero (0) under severe stress, when soil moisture losses were between 0.0882 and $0.0954 \mathrm{~g} . \mathrm{g}^{-1}$, i.e., in the range of 25 to 38 days without water supply. With the progression of the drought, $A, g_{s}$, and $\mathrm{Ci}$ were decreased jointly and gradually. However, the Ci (Fig. 2 B) was increased, when the limitation became non-stomatal, possibly due to the inactivation of the RuBisCO enzyme under severe stress (Ping et al., 2015).

Along with $g_{s}$, transpiration $(E)$ was also decreased with the progressive loss of soil moisture and drought time (Fig. $1 \mathrm{C}$ ). The polynomial functional relationship explained this response. It indicates that for each lost ( $\left.\mathrm{g} . \mathrm{g}^{-1}\right)$ of soil moisture, the $E$ can decrease to $113.5 \mathrm{mmol} \mathrm{H}_{2} \mathrm{O} \mathrm{m}^{-2}$. $\mathrm{s}^{-1}$ with a linear effect, and a linearity deviation of $401.9 \mathrm{mmol} \mathrm{H}_{2} \mathrm{O} \mathrm{m}^{-2}$. $\mathrm{s}^{-1}$.

The decrease in photosynthesis was linearly related to the reduction of intercellular $\mathrm{CO}_{2}(\mathrm{Ci})$ until a loss of $0.0882 \mathrm{~g} \cdot \mathrm{g}^{-1}$ of soil water content (SWC) happened at 25 th DD, for which an average concentration of $97.6 \pm 49.4 \mu \mathrm{mol}$ of intercellular $\mathrm{CO}_{2}$ $\mathrm{m}^{-2} . \mathrm{s}^{-1}$ was estimated (Fig. 2A). However, when the stress was more severe, the concentration of $\mathrm{Ci}$ was increased, and the photosynthesis reached values close to zero (Fig. 2B). This increase in $\mathrm{Ci}$ registered would be related to the inhibition of photosynthesis (Lawlor and Tezara, 2009).

The intrinsic water use efficiency $\left(A / g_{s}\right)$ increased from the moment the water supply was suspended until day 21 , when the loss of soil water content reached $0.0827 \mathrm{~g} . \mathrm{g}^{-1}$. The increase was linear at a rate of $2,025.6 \mu \mathrm{mol}$ of $\mathrm{CO}_{2}$ per mol of $\mathrm{H}_{2} \mathrm{O}$ for each g.g ${ }^{-1}$ of water lost through evapotranspiration (Fig. 3A). This increase, along with decreases in photosynthesis, stomatal conductance, and transpiration in response to water deficit has been reported previously (Singh and Reddy, 2011; Rivas et al., 2016). However, in the periods from 21 to 38 DD with water losses between 0.0827 and $0.0954 \mathrm{~g} \cdot \mathrm{g}^{-1}, A / g_{s}$ was decreased linearly at a rate of 5,179.8 $\mu \mathrm{mol}$ of $\mathrm{CO}_{2} \mathrm{~mol}^{-1} \mathrm{H}_{2} \mathrm{O}$ for each g.g $\mathrm{g}^{-1}$ of water lost by evapotranspiration (Fig. 3B), possibly as a consequence of a non-stomatal limitation (Rivas et al., 2016).

The ratio of intercellular and environmental $\mathrm{CO}_{2}$ concentrations $(\mathrm{Ci} / \mathrm{Ca})$ turned out to be inverse of $A / g_{s}$ (Figs. $3 C$ and $3 \mathrm{D}$ ). The $A / g_{s}$ was increased with a decrease in $g_{s}$. Nonetheless, the highest increases were observed with gs values lower than $0.04 \mu \mathrm{mol}$ of $\mathrm{H}_{2} \mathrm{O} \mathrm{m}^{-2}$. $\mathrm{s}^{-1}$, explained by a potential model (Fig. 4A) corresponding to soil water losses between 0.0827 and $0.0954 \mathrm{~g} \cdot \mathrm{g}^{-1}$ in the range of 21-38 DD. Simultaneously, high $\mathrm{Ci} / \mathrm{Ca}$ values were associated with high gs, which relationship explained by a hyperbolic model (Fig. 4B). However, when the hydric stress was very severe, the very low values of $g_{s}$ were associated with increases in $\mathrm{Ci} / \mathrm{Ca}$, which could be related to a non-stomatal limitation (Brodribb, 1996). In turn, Lawlor and Tezara (2009) considers that the stomatal limitation leads to a decrease of photosynthesis $(A)$ as well as of $\mathrm{CO}_{2}$ concentration $(\mathrm{Ci})$ in the intercellular spaces of the leaf, a situation that inhibits the activity of the enzymes nitrate reductase and sucrose phosphate synthase.

\section{Chlorophyll fluorescence}

The quantum yield of photosynthesis (DPSII) was decreased as the water deficit became stronger, indicating a lower percentage of excited electrons bound to photosystem II to convert light energy into carbohydrates (Kuhlgert et al., 2016). The decreases found were $28.4 \%, 40.3 \%$ and $43.5 \%$ at 17,21 and $38 \mathrm{DD}$, respectively (Fig. 5A). In a sense, when drought stress became more severe, the quantum yield of photosynthesis became increasingly lower. There is sufficient evidence of a linear correlation between $\Phi$ PSII and $\Phi \mathrm{CO}_{2}$, and the quantum yield of $\mathrm{CO}_{2}$ assimilation in the leaf (Surabhi et al., 2009). So, the results obtained in this study agreed with the progressive decrease of photosynthesis during the drought period.

In contrast, the non-photochemical quantum yield (DNPQ) associated with non-photochemical decay (quenching) were increased as the drought became more severe, indicating that all the genotypes regulated the excess energy that could cause damage to the photosystems. This dissipation of excess radiant energy as heat in the complex PSII antenna is a photoprotection induced by light through the thermal dissipation of energy. This is carried out in the xanthophyll cycle (Jiménez-Suancha et al., 2015, Ping et al., 2015). Furthermore, the increases were $388.5 \%$ at $17 \mathrm{DD}, 484.3 \%$ at $21 \mathrm{DD}$, and $398.0 \%$ at $38 \mathrm{DD}$. In general, the photoprotection of the genotypes was 4-5 times higher, compared to the one of the well-hydrated plants (Fig. 5 B).

The relative chlorophyll content was decreased with drought, but it was significant at 21 and 38 days, when it decreased by $19.4 \%$ and $25.4 \%$, respectively (Fig. 5C). This decrease in chlorophyll levels in the leaves could be related to the reduction of the relative water content of the leaves (Merwad et al., 2018). However, in this research, there were no significant 
Table 1. Plant height and leaves number of nine cowpea genotypes under drought and irrigation conditions.

\begin{tabular}{|c|c|c|c|c|}
\hline \multirow[b]{2}{*}{ Genotype } & \multicolumn{2}{|c|}{ Plant height $(\mathrm{cm})$} & \multicolumn{2}{|c|}{ Leaves number } \\
\hline & Drought & Irrigation & Drought & Irrigation \\
\hline Caupicor-50 & $17.63^{\mathrm{a}^{*}}$ & $116.50^{\mathrm{a}}$ & $6.25^{\mathrm{a}}$ & $14.00^{\mathrm{a}}$ \\
\hline LC-006-016 & $16.75^{\mathrm{a}}$ & $56.25^{\mathrm{b}}$ & $5.25^{b}$ & $11.25^{\mathrm{c}}$ \\
\hline LC-029-016 & $17.63^{\mathrm{a}}$ & $43.13^{b}$ & $6.75^{a}$ & $10.75^{c}$ \\
\hline LC-036-016 & $17.38^{\mathrm{a}}$ & $42.00^{b}$ & $6.25^{\mathrm{a}}$ & $10.25^{c}$ \\
\hline LC-021-016 & $17.50^{\mathrm{a}}$ & $55.25^{b}$ & $6.25^{a}$ & $10.75^{c}$ \\
\hline LC-005-016 & $16.50^{\mathrm{a}}$ & $44.75^{b}$ & $6.00^{\mathrm{ab}}$ & $10.75^{c}$ \\
\hline LC-009-016 & $18.25^{\mathrm{a}}$ & $65.00^{\mathrm{ab}}$ & $6.00^{\mathrm{ab}}$ & $11.25^{\mathrm{bc}}$ \\
\hline LC-014-016 & $18.00^{\mathrm{a}}$ & $51.50^{\mathrm{b}}$ & $6.25^{\mathrm{a}}$ & $11.00^{\mathrm{bc}}$ \\
\hline LC-002-016 & $17.25^{\mathrm{a}}$ & $90.00^{\mathrm{ab}}$ & $6.75^{a}$ & $12.25^{\mathrm{ab}}$ \\
\hline Mean & $17.43 \pm 2.11$ & $62.71 \pm 25.02$ & $6.19 \pm 0.52$ & $11.36 \pm 1.32$ \\
\hline
\end{tabular}

* Means with the same letter do not differ statistically according to the Tukey test at $5 \%$

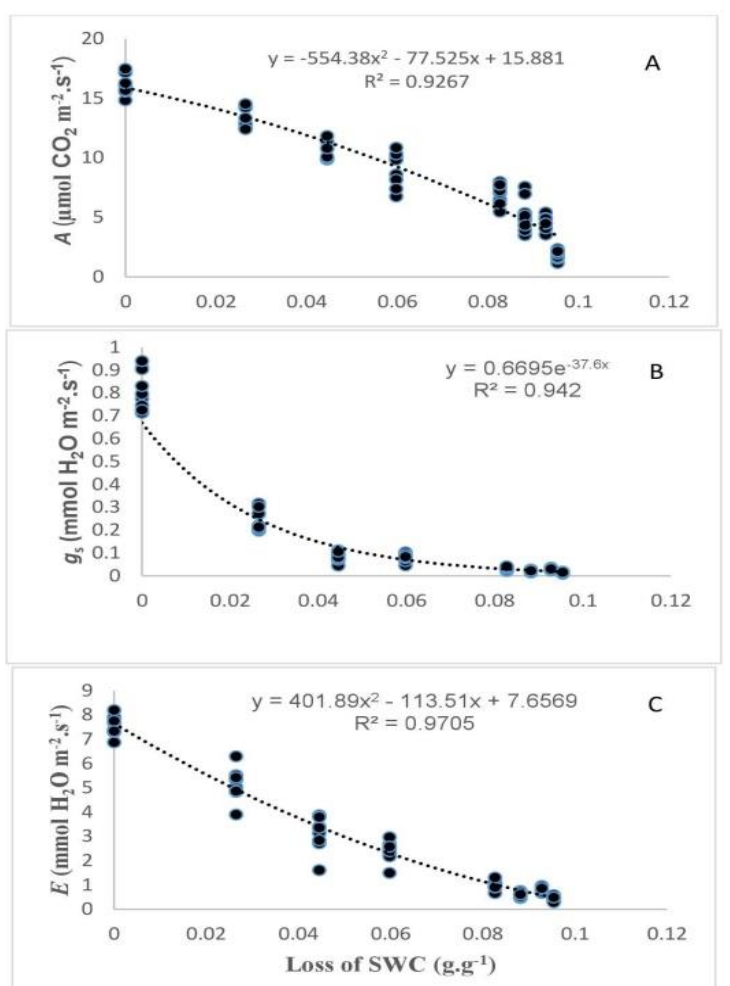

Fig 1. Relationship between loss of soil water content (SWC) and A) net photosynthesis $(A)$; B) stomatal conductance $\left(g_{\mathrm{s}}\right)$; and C) transpiration $(E)$ for nine cowpea genotypes. 


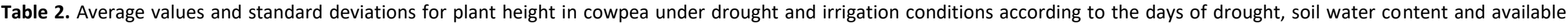
water content (cultivated under greenhouse conditions).

\begin{tabular}{|c|c|c|c|c|c|}
\hline $\begin{array}{l}\mathrm{DD} \\
\text { (d) }\end{array}$ & $\begin{array}{c}\text { SWC } \\
(\%)\end{array}$ & $\begin{array}{c}\text { AWC } \\
(\%)\end{array}$ & $\begin{array}{l}\text { Plant height under drought conditions } \\
\qquad(\mathrm{cm})\end{array}$ & $\begin{array}{l}\text { Plant height under irrigation conditions } \\
\qquad(\mathrm{cm})\end{array}$ & $\begin{array}{l}\text { Difference } \\
(\mathrm{cm})^{\#}\end{array}$ \\
\hline 0 & 25.25 & 9.03 & $11.90 \pm 1.48$ & $12.26 \pm 2.12$ & $0.36^{\text {ns }}$ \\
\hline 2 & 23.77 & 7.55 & $13.35 \pm 1.74$ & $13.22 \pm 2.25$ & $-1.13^{\mathrm{ns}}$ \\
\hline 8 & 20.80 & 4.58 & $14.39 \pm 2.26$ & $14.71 \pm 3.14$ & $0.32^{\mathrm{ns}}$ \\
\hline 14 & 18.67 & 2.45 & $15.19 \pm 2.21$ & $19.01 \pm 5.37$ & $3.82 * *$ \\
\hline 21 & 16.98 & 0.76 & $16.07 \pm 1.94$ & $32.81 \pm 17.99$ & $16.74 * *$ \\
\hline 27 & 16.25 & 0.03 & $16.40 \pm 1.74$ & $52.19 \pm 28.46$ & $35.79 * *$ \\
\hline 33 & 15.71 & ND & $17.06 \pm 1.85$ & $62.35 \pm 33.14$ & $45.29 * *$ \\
\hline 38 & 15.27 & ND & $17.50 \pm 1.94$ & $62.85 \pm 32.69$ & $45.35 * *$ \\
\hline
\end{tabular}

(
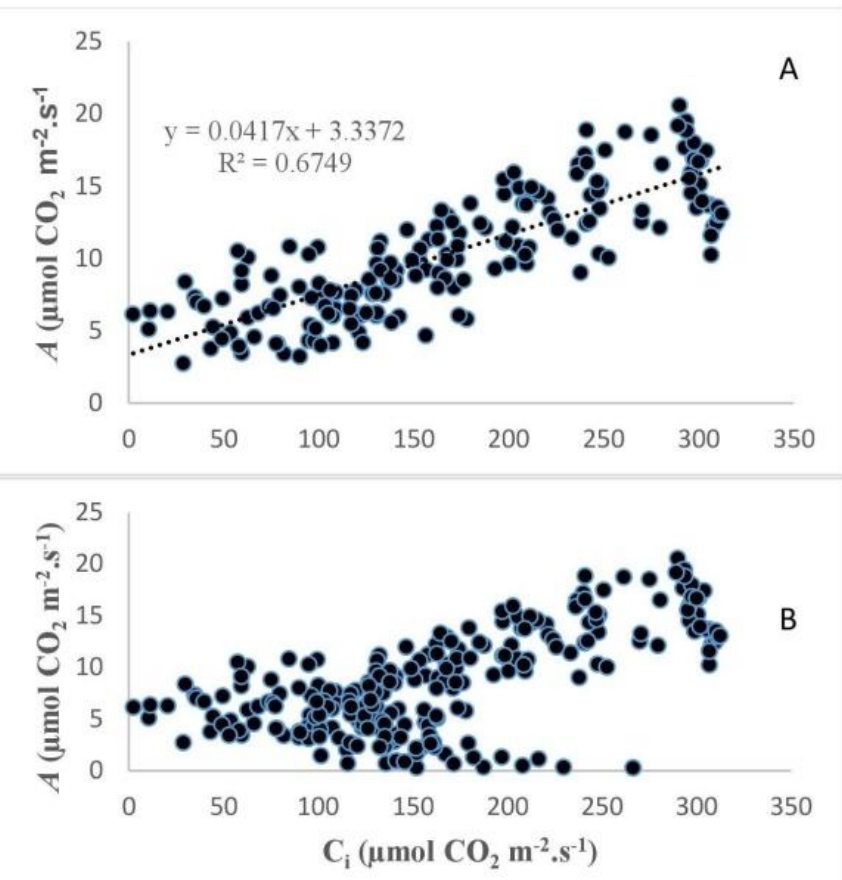

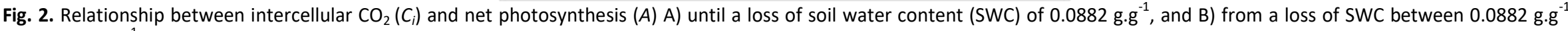
and 0.0954 g.g ${ }^{-1}$ for nine cowpea genotypes. 
Table 3. Vegetative, reproductive, total aerial and root biomass values of nine cowpea genotypes under drought and irrigation conditions.

\begin{tabular}{|c|c|c|c|c|c|c|c|c|}
\hline \multirow{2}{*}{ Genotype } & \multicolumn{2}{|c|}{ Vegetative biomass (g) } & \multicolumn{2}{|c|}{ Reproductive biomass (g) } & \multicolumn{2}{|c|}{ Total aerial biomass $(\mathrm{g})$} & \multicolumn{2}{|c|}{ Root biomass (g) } \\
\hline & Drought & Irrigation & Drought & Irrigation & Drought & Irrigation & Drought & Irrigation \\
\hline Caupicor-50 (control) & $1.585^{\mathrm{a}}$ & $6.035^{\mathrm{a}}$ & 0.044 & $9.853^{\mathrm{a}}$ & $1.629^{\mathrm{a}}$ & $15.888^{a}$ & $1.499^{\mathrm{a}}$ & $4.480^{\mathrm{a}}$ \\
\hline LC-006-016 & $1.668^{\mathrm{a}}$ & $6.407 \underline{a}$ & 0.200 & $7.256^{\mathrm{ab}}$ & $1.449 \mathrm{a}$ & $13.663^{a}$ & $1.132^{\mathrm{a}}$ & $3.252^{\mathrm{a}}$ \\
\hline LC-002-016 & $1.598^{\mathrm{a}}$ & 5.983 a & 0.002 & $8.972^{\mathrm{ab}}$ & $1.671 \mathrm{a}$ & 14.955a & $1.179^{\mathrm{a}}$ & $2.643^{\mathrm{a}}$ \\
\hline LC-009-016 & $1.249^{\mathrm{a}}$ & $6.613 a$ & - & $4.705^{\mathrm{ab}}$ & $1.660 \mathrm{a}$ & $11.318^{\mathrm{a}}$ & $1.219^{\mathrm{a}}$ & $4.201^{\mathrm{a}}$ \\
\hline LC-014-016 & $1.660^{\mathrm{a}}$ & $6.904 \mathrm{a}$ & 0.009 & $5.688^{\mathrm{ab}}$ & $1.713^{\mathrm{a}}$ & $15.592^{\mathrm{a}}$ & $1.218^{\mathrm{a}}$ & $4.358^{\mathrm{a}}$ \\
\hline LC-005-016 & $1.704^{\mathrm{a}}$ & $7.220 \mathrm{a}$ & - & $8.972^{a b}$ & $1.598^{\mathrm{a}}$ & $11.070^{\mathrm{a}}$ & $1.359^{\mathrm{a}}$ & $4.458^{\mathrm{a}}$ \\
\hline LC-029-016 & $1.767^{\mathrm{a}}$ & $6.211 \underline{a}$ & - & $3.506^{\mathrm{ab}}$ & $1.718^{\mathrm{a}}$ & $9.718^{\mathrm{a}}$ & $1.338^{\mathrm{a}}$ & $4.418^{\mathrm{a}}$ \\
\hline LC-036-016 & $1.718^{\mathrm{a}}$ & $6.304 \underline{a}$ & - & $4.852^{\mathrm{ab}}$ & $1.623 a$ & $11.156^{\mathrm{a}}$ & $1.584^{\mathrm{a}}$ & $4.380^{\mathrm{a}}$ \\
\hline LC-021-016 & $1.623^{\mathrm{a}}$ & 6.860 a & - & $2.012^{b}$ & $1.767 \underline{a}$ & $8.873^{\mathrm{a}}$ & $1.338^{\mathrm{a}}$ & $3.051^{\mathrm{a}}$ \\
\hline Mean & 1.619 & 6.504 & - & 5.633 & 1.648 & 12.368 & 1.313 & 3.916 \\
\hline CV (\%) & 19.97 & 26.77 & - & 58.67 & 18.98 & 28.31 & 24.58 & 50.10 \\
\hline$P$-value & $0.555^{\mathrm{ns}}$ & $0.980^{\text {ns }}$ & & $0.038^{\mathrm{ns}}$ & $0.942^{\text {ns }}$ & $0.109^{\mathrm{ns}}$ & $0.557^{\mathrm{ns}}$ & $0.815^{\mathrm{ns}}$ \\
\hline
\end{tabular}

Means with the same letter or letters do not differ statistically according to the Tukey test $(\alpha=0.05)$. CV $=$ coefficient of variation. ${ }^{\text {ns }}=$ not significant $(p \geq 0.05)$.

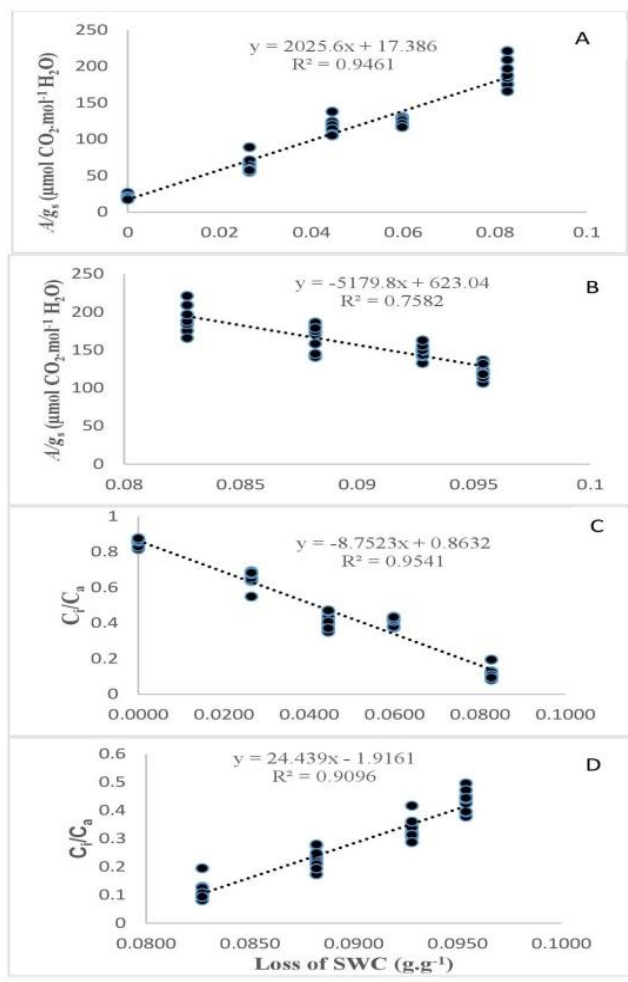

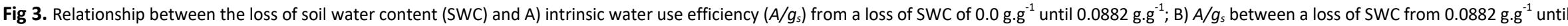

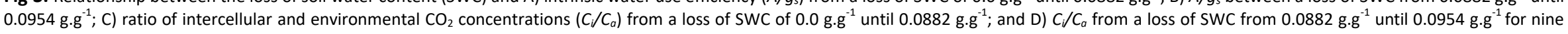
cowpea genotypes. 


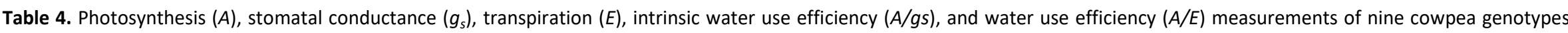
under drought and irrigation conditions.

\begin{tabular}{|c|c|c|c|c|c|c|c|c|c|c|}
\hline \multirow{2}{*}{ Genotypes } & \multicolumn{2}{|l|}{$A$} & \multicolumn{2}{|l|}{$g_{s}$} & \multicolumn{2}{|l|}{$E$} & \multicolumn{2}{|l|}{$A / g_{\mathrm{s}}$} & \multicolumn{2}{|l|}{$A / E$} \\
\hline & Drought & Irrigation & Drought & Irrigation & Drought & Irrigation & Drought & Irrigation & Drought & Irrigation \\
\hline Caupicor-50 & $5.47^{a}$ & $21.11^{\mathrm{a}}$ & $0.021 \underline{a}$ & $0.638^{a}$ & $0.66^{\mathrm{a}}$ & $9.70^{a}$ & $319.6^{a}$ & 35.3 a & $9.03^{a}$ & $2.18^{\mathrm{ab}}$ \\
\hline LC-002-016 & $7.73^{\mathrm{a}}$ & $19.54^{a}$ & $0.041 \underline{a}$ & $0.507 \underline{a}$ & $1.31^{\mathrm{a}}$ & $8.85^{\mathrm{a}}$ & $197.0^{\mathrm{a}}$ & $42.3^{\mathrm{a}}$ & $6.16^{\mathrm{a}}$ & $2.22^{\mathrm{ab}}$ \\
\hline LC-005-016 & $7.49 \underline{a}$ & $21.42^{\mathrm{a}}$ & $0.038^{a}$ & 0.740 a & $1.32^{\mathrm{a}}$ & $10.17 \underline{a}$ & 242.7 a & $29.0^{\mathrm{a}}$ & $6.77^{a}$ & $2.11^{b}$ \\
\hline LC-006-016 & $6.48^{a}$ & $19.21^{a} \underline{a}$ & $0.044 \underline{a}$ & $0.512^{\mathrm{a}}$ & $1.25^{\mathrm{a}}$ & $9.11^{\mathrm{a}}$ & $154.0^{\mathrm{a}}$ & $37.7^{\mathrm{a}}$ & $5.54 \underline{a}$ & $2.11^{\mathrm{b}}$ \\
\hline LC-009-016 & $7.80^{\mathrm{a}}$ & 17.16a & $0.045 \underline{a}$ & $0.364 \underline{a}$ & $1.31^{\mathrm{a}}$ & 6.69a & $194.4^{a} \underline{a}$ & $71.9^{a}$ & $6.22^{a}$ & $2.75 \underline{a}$ \\
\hline LC-014-016 & $7.24 \underline{a}$ & 20.04 a & $0.039 \underline{a}$ & 0.663 a & $1.31^{\mathrm{a}}$ & $9.54 \underline{a}$ & $200.8^{a}$ & $35.6 \underline{a}$ & $6.25^{a}$ & $2.13^{b}$ \\
\hline LC-021-016 & $7.05^{\mathrm{a}}$ & $21.65 a$ & $0.035 \underline{a}$ & $0.636 \mathrm{a}$ & $1.13^{\mathrm{a}}$ & $9.71^{a}$ & $273.7 \underline{a}$ & $37.5^{\mathrm{a}}$ & $7.54^{\mathrm{a}}$ & $2.24^{\mathrm{ab}}$ \\
\hline LC-029-016 & $6.14 \underline{a}$ & $18.50 \mathrm{a}$ & $0.048 \underline{a}$ & $0.640 \mathrm{a}$ & $0.88^{a}$ & $8.64^{\mathrm{a}}$ & $308.1 \underline{a}$ & $40.6 \underline{a}$ & $8.76^{\mathrm{a}}$ & $2.16^{\mathrm{ab}}$ \\
\hline LC-036-016 & $7.50^{\mathrm{a}}$ & $20.46 \underline{a}$ & $1.61 \mathrm{a}$ & 0.613 a & $1.52^{\mathrm{a}}$ & $9.07 \underline{a}$ & $175.4^{a} \underline{a}$ & $36.1^{\mathrm{a}}$ & $5.93^{a}$ & $2.27^{\mathrm{ab}}$ \\
\hline Mean & 6.99 & 19.76 & 0.037 & 0.583 & 1.18 & 8.98 & 233.76 & 41.28 & 6.99 & 2.25 \\
\hline CV (\%) & 31.39 & 12.07 & 54.42 & 49.69 & 58.34 & 17.80 & 50.16 & 40.74 & 33.24 & 10.99 \\
\hline$P>F$ & $0.824^{\mathrm{ns}}$ & $0.267^{\mathrm{ns}}$ & $0.681^{\text {ns }}$ & $0.807^{\text {ns }}$ & $0.792^{\mathrm{ns}}$ & $0.219^{\text {ns }}$ & $0.497^{\mathrm{ns}}$ & $0.083^{\mathrm{ns}}$ & $0.398^{\mathrm{ns}}$ & $0.034^{*}$ \\
\hline
\end{tabular}

$\begin{aligned} & \text { Means with the same or same letters do not differ sta } \\ & n s\end{aligned}=$ not significant $(p \geq 0.05) ;{ }^{*}=$ significant $(p \geq 0.05)$.

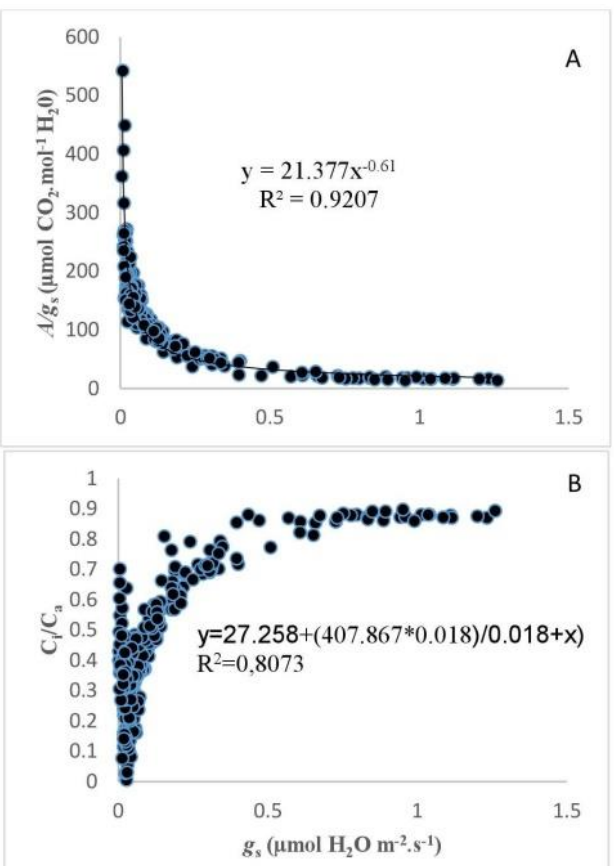

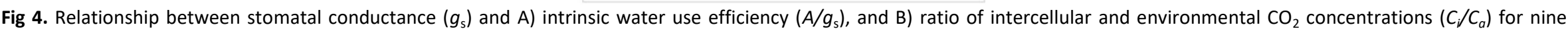
cowpea genotypes. 
Table 5. The relationship between two principal components and Pearson's correlation coefficients of eight variables (Var.) used in the principal component analysis.

\begin{tabular}{|c|c|c|c|c|c|c|c|c|c|}
\hline Var. & $\mathrm{CP} 1$ & $\mathrm{CP} 2$ & TAB & VB & $\mathrm{PH}$ & $A$ & $g_{\mathrm{s}}$ & $E$ & $A / g_{\mathrm{s}}$ \\
\hline TAB & 0.2421 & 0.5038 & & & & & & & \\
\hline VB & 0.2354 & 0.5594 & $0.9060 * * *$ & & & & & & \\
\hline PLH & 0.2793 & 0.4331 & $0.7294 *$ & $0.8094 * * *$ & & & & & \\
\hline$A$ & -0.3297 & 0.3428 & $-0.1421^{\mathrm{ns}}$ & $-0.0691^{\mathrm{ns}}$ & $-0.1441^{n s}$ & & & & \\
\hline$g_{s}$ & -0.4308 & 0.1453 & $-0.3725^{n s}$ & $-0.3337^{\mathrm{ns}}$ & $-0.4483^{\mathrm{ns}}$ & $0.8114 * * *$ & & & \\
\hline$E$ & -0.3932 & 0.2930 & $-0.1480^{\mathrm{ns}}$ & $-0.0899^{\mathrm{ns}}$ & $-0.3054^{\mathrm{ns}}$ & $0.8685^{* * *}$ & $0.9514 * * *$ & & \\
\hline$A / g_{s}$ & 0.4218 & -0.0696 & $0.3739^{\mathrm{ns}}$ & $0.4473^{\mathrm{ns}}$ & $0.4839^{\mathrm{ns}}$ & $(-0.6403)^{*}$ & $(-0.9398)^{* * *}$ & $(-0.8553)^{* * *}$ & \\
\hline$A / E$ & 0.4255 & -0.1280 & $0.3200^{\mathrm{ns}}$ & $0.3733^{n s}$ & $0.4574^{\mathrm{ns}}$ & $(-0.7291)^{*}$ & $(-0.9536)^{* * *}$ & $(-0.9088)^{* * *}$ & $0.9827^{* * *}$ \\
\hline
\end{tabular}

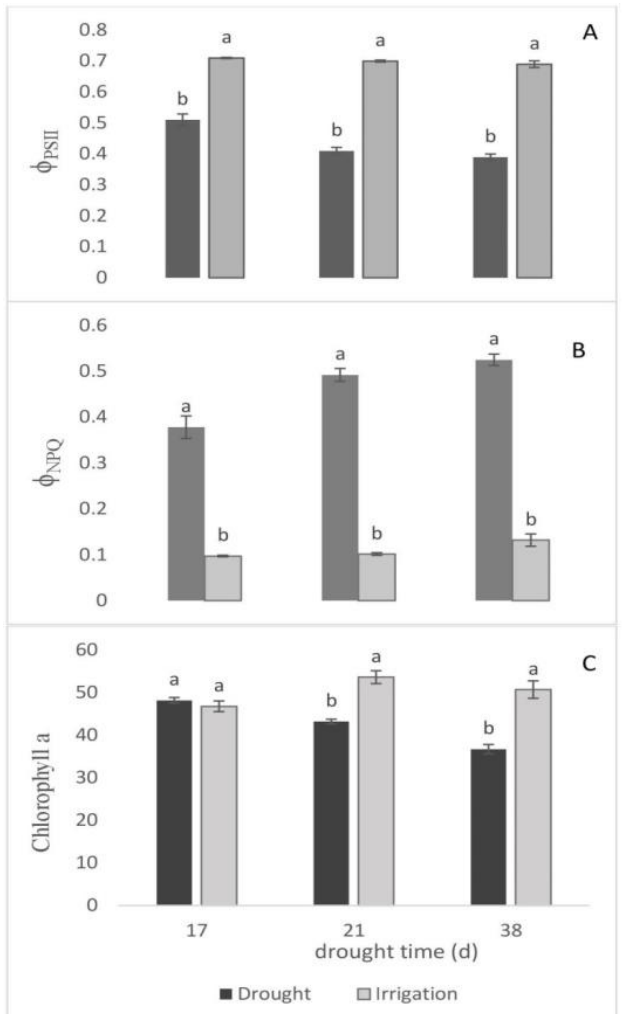

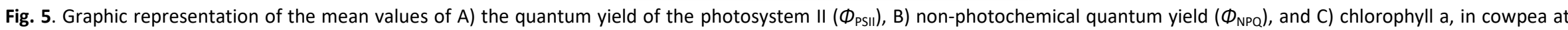
17,21 and 38 days under drought and irrigation conditions. 


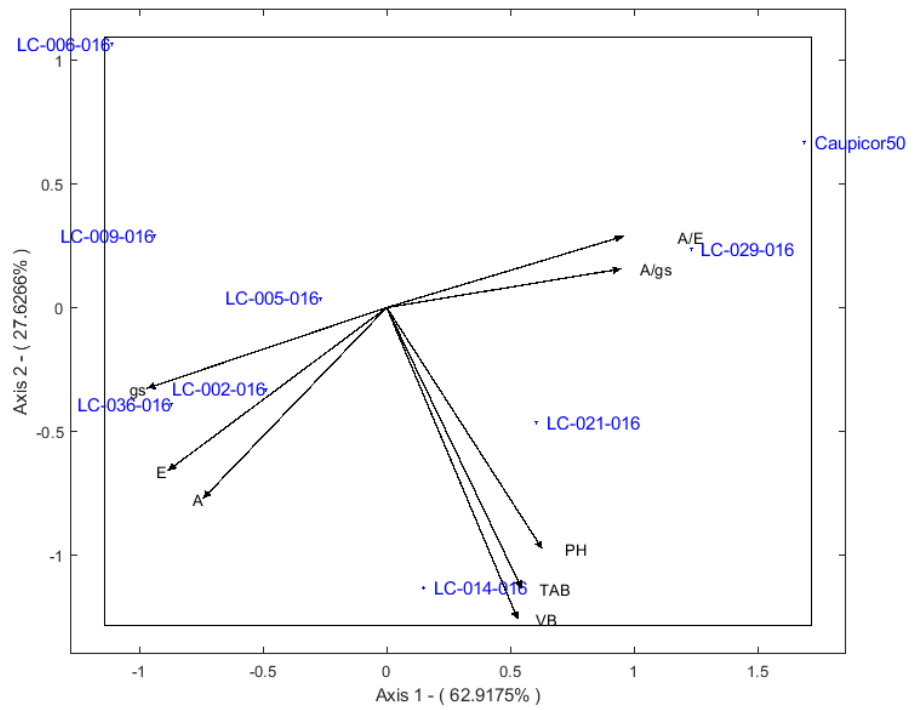

Fig 6. PCA-biplot representation of cowpea genotypes and their correlated characteristics. CP1: First principal component; CP2: Second principal component; TAB: total aerial biomass; VB: vegetative biomass; $\mathrm{PH}$ : plant height; $A$ : net photosynthesis; $g_{s}$ : stomatal conductance; $E$ : transpiration; $A / g_{s}$ : intrinsic water use efficiency; $A / E$ : water use efficiency. $\mathrm{PH}, A, g_{s}, E, A / g_{s}$, and $A / E$ were evaluated at $21 \mathrm{DD} ; \mathrm{TAB}$ and $\mathrm{VB}$ were assessed at the end of the trial, i.e., at $38 \mathrm{DD}$.

differences in the moisture percentage of the leaf biomass, when comparing the two conditions to which the plants were subjected, i.e., drought and irrigation, with averages of $79.06 \%$ and $79.24 \%$, respectively, at the end of the trial.

\section{Effects of drought on cowpea}

By joint analysis of the characteristics of growth, biomass distribution, gas exchange, and chlorophyll fluorescence, a high positive correlation was found between total aerial biomass, vegetative biomass, plant height, and water use efficiencies $\left(A / g_{s}\right.$ and $\left.A / E\right)$. Likewise, high negative correlations between these five variables with net photosynthesis $(A)$, stomatal conductance $\left(g_{s}\right)$ and transpiration $(E)$ were found. However, there was no significant correlation with $\Phi \mathrm{PII}, \Phi \mathrm{NPQ}$ and chlorophyll a.

The principal components analysis (PCA) was performed with the eight correlated variables. It showed that the first two components explained $90.54 \%$ of the total variation between genotypes (Table 5). In general, the PCA suggests that genotypes with greater efficiency in the use of water and those with higher biomass production would have a higher resistance to drought.

The first component explained $62.92 \%$ of the total variance, and their eigenvectors for $A / E$ and $A / g_{s}$ are positive and higher. These contrast with the negatives ones found for $A, g_{s}$ and $E$. This first component indicates the importance of water use efficiency under drought, whose highest values are indicators of drought resistance (Singh and Reddy, 2011, Belko et al., 2012). The genotypes with the highest records of water use efficiency were Caupicor-50 and LC-29-016 (Fig. 6). Hence, these genotypes could be used in regions with limited water availability in the soil.
The second component explained $27.63 \%$ of the total variability and expresses the importance of biomass production and growth in height, characters slightly contrasting with the water use efficiencies $\left(A / g_{\mathrm{s}}\right.$ and $\left.A / E\right)$ because of the very low magnitudes of negative eigenvectors. The genotypes with the highest biomass estimates were LC021-016, LC-014-016, and LC-029-016 (Fig. 6). Hence, these genotypes could be cultivated in regions, where there are no water availability limitations in the soil. On the other hand, LC009-016, LC-002-016, LC-036-016, and LC-005-016 are characterized by showing high values of photosynthesis, stomatal conductance, and transpiration, but they are the least efficient in the use of water, recording an intermediate biomass production. Moreover, LC-006-016 showed low values of $A, E, A / g_{\mathrm{s}} A / E$, vegetative biomass, total aerial biomass, and plant height, possibly because it is a very precocious genotype resistant to drought.

\section{Materials and methods}

\section{Experimental conditions and plant material}

The experiments were carried out in a greenhouse covered with polyethylene (roof and walls) and with an anti-aphid mesh, located on the campus of Universidad de Córdoba, Colombia ( 8 - 48' N, 78 53' W). Eight (8) genotypes of the breeding program of the Faculty of Agricultural Sciences of Universidad de Cordoba: LC-006-016, LC-029-016, LC-036-016, LC-021-016, LC-005-016, LC-009-016, LC-014-016, LC-002-016, plus the commercial genotype Caupicor-50 (control) were used. Genotypes were chosen for performance and nutritional quality, under Colombian-Caribbean-normal conditions. All plants were cultivated in transparent tubular cylindrical containers of $120 \mathrm{~cm}$ high and with $7.5 \mathrm{~cm}$ in diameter covered 
by PVC tubes (capacity of 5,300 $\mathrm{cm}^{3}$ ). For each experiment, a completely randomized design with 9 treatments (genotypes) and 4 repetitions (containers spaced at $0.60 \mathrm{~m} \times 0.30 \mathrm{~m}$ ) was used. The containers were filled with loam-clay-silt soil from the Sinú valley, with silt-loam texture, and physically-and chemically characterized; soil moisture content at field capacit (-0.033Mpa) of $25.25 \%$ and $16.22 \%$ at $-1.5 \mathrm{Mpa}$, available water content (AWC) for plants $9.03 \%$ (equivalent to $0.0903 \mathrm{~g} \mathrm{~g}^{-1}$ ).

The soil was solarized for 40 days. The seeds were treated with Carboxin + Captan (3.0 g per kilogram of seed). Three seeds were sown per container and then seedlings were thinned seven days after sowing to leave only one. In the first experiment, the plants were irrigated until 21 days after sowing (DDS) to maintain the moisture content at $-0.033 \mathrm{Mpa}$ and then the irrigation was suspended for 38 days. In the second experiment, they were watered until the 59th day. Weight loss by evapotranspiration was recorded in the experimental units every three days, using a digital electronic scale to determine the soil water content.

\section{Plant growth and biomass distribution}

From 21 to 59 DAS, direct measurements of plant height, and the number of unifoliate and trifoliate leaves per plant were taken every four days. The dry biomass of leaves, stems, flowers, flower peduncles, pods, seeds, vegetative biomass, reproductive biomass, and total biomass was measured at the end of the experiment (59 DAS and 38 days of drought (DD). The measurements, in grams, were made with an Adventurer precision balance (OHAUS, NJ, USA), after drying the samples in an oven at $70^{\circ} \mathrm{C}$ for $24 \mathrm{~h}$.

\section{Gas exchange and chlorophyll fluorescence}

Net photosynthesis $(A)$, stomatal conductance $\left(g_{s}\right)$, transpiration $(E)$, intrinsic water use efficiency $\left(A / g_{s}\right)$ and transpiration efficiency $(A / E)$ were measured every seven days with the infrared gas analyzer brand LICOR 6400 (Lincoln, Nebraska, USA). Measurements were made on a leaflet of the second or third fully expanded leaf between 9:30 and 12:30 a.m. The equipment was programmed with the following reference values: $\mathrm{CO}_{2}$ concentration of $380 \mathrm{ppm}$, photosynthetically active radiation (PAR) of $1,000 \mu \mathrm{mol}$ of photons $\mathrm{m}^{-2} \cdot \mathrm{s}^{-1}$ and a leaf area of $6 \mathrm{~cm}^{2}$. Quantum yield of the photosystem II (ФPSII), ratio of incoming light that goes towards non-photochemical quenching (DNPQ) and relative chlorophyll content measurements were taken with the MultispeQ v2.0 equipment (Michigan State University, USA) at 17, 21 and 38 DD. ФPSII is essentially the percentage of incoming light (electrons excited) that goes into photosystem II. Photosystem II is where most light energy is converted into carbohydrates. It is calculated with the following equation: DPSII $=\frac{F^{\prime} m-F s}{F^{\prime} m}$; where $F_{m}^{\prime}$ is the maximum chlorophyll fluorescence during a light saturation flash $>6.000 \mu \mathrm{mol} \mathrm{m}^{-2} \mathrm{~s}^{-1}$ and a duration of $0.8 \mathrm{~s} ; F_{s}$ is the steady-state fluorescence (Surabhi et al. 2009). ФNPQ indicates how plant can regulate the excess energy in a way to reduce damage to the plant. Accordingly, the plant regulates the excess energy in a way that it also reduces plant damage (Kuhlgert et al., 2016).

\section{Statistical analysis}

The response variables were analyzed using descriptive statistics, analysis of variance, Tukey test at $5 \%$ and Student's t-tests. The functional relationships between plant height, gas exchange parameters and soil moisture loss were tested for linear, polynomial, exponential, logarithmic and potential models, and the best fit equations were selected following the diagnostic criteria (Rincon, 2009). For the GLM, REG and IML procedures of SAS software version 9.2 were used (SAS, 2008). For the joint analysis of growth, biomass distribution, gas exchange, water use efficiency and chlorophyll fluorescence variables, principal components analysis (PCA) was performed with the SAS software version 9.2 (SAS, 2008). Further, a biplot representation with the averages of the eight characteristics that were correlated was carried out using the MultBiplot software.

\section{Conclusions}

Plant height and number of leaves in nine genotypes were decreased with increasing drought. The first reached $10.8 \%$ compared to the plants under irrigation and developed six to seven leaves, in contrast to the 11-14 developed by plants under irrigation. The vegetative biomass was decreased $76.3 \%$ under drought. Meanwhile, the reproductive biomass was only expressed in genotypes Caupicor-50 (control), LC-006-016, LC021-016, and LC-014-016. The rest of the genotypes avoided drought, remaining in their vegetative phase. Photosynthesis, stomatal conductance, and transpiration were decreased $64.6 \%, 93.1 \%$, and $86.9 \%$, respectively, compared to irrigated plants. The intrinsic water use efficiency $\left(A / g_{s}\right)$ was increased almost six times. However, it gradually decreased with an increase in drought from a loss of soil water content higher than $0.0827 \mathrm{~g} . \mathrm{g}^{-1}$, suggesting non-stomatal limitation of photosynthesis in accordance with increases in the proportion of intercellular and environmental $\mathrm{CO}_{2}$ concentrations $\left(C_{i} / C_{a}\right)$ to low values of stomatal conductance $\left(g_{s}\right)$. The quantum yield of photosynthesis (DPSII) was decreased $28.4 \%, 40.3 \%$ and $43.5 \%$ at 17,21 and 38 days of drought, respectively. The photoprotection indicated by the non-photochemical quantum yield ( $\triangle N P Q$ ) was 4-5 times higher than in the irrigated plants. The relative content of chlorophyll in SPAD units decreased significantly in a severe drought condition when soil water content losses were higher than $0.0827 \mathrm{~g} . \mathrm{g}^{-1}$. The principal components analysis and the biplot allowed classifying genotypes, as follows: (a) genotypes characterized by showing high water use efficiency: LC-02916 and Caupicor-50 (control); (b) genotypes with higher growth and biomass development: LC-2116 and LC-01416; and (c) genotypes with higher photosynthesis, stomatal conductance, and transpiration: LC036-016, LC-021-016, and LC-005-016.

\section{Conflicts of interest}

The authors declare that there are no conflicts of interest in this study. 


\section{Acknowledgments}

The Authors express their gratitude to Universidad de Córdoba, Colciencias and Fundación Promotora Canal del Dique for their support and for financing this research, and the Agronomical Engineering students as well as the personnel of the Plant Breeding and Physiology laboratories of Universidad de Córdoba.

\section{References}

Agbicodo E, Fatokun C, Muranaka S, Visser R, Linden C (2009) Breeding drought tolerant cowpea: Constraints, accomplishments, and future prospects. Euphytica. 167: 353370.

Belko N, Zaman-Allah M, Cisse N, Diop NN, Zombre G, Ehlers JD, Vadez V (2012) Lower soil moisture threshold for transpiration decline under water deficit correlates with lower canopy conductance and higher transpiration efficiency in drought-tolerant cowpea. Funct Plant Biol. 39(4):306-322.

Brodribb T (1996) Dynamics of Changing intercellular $\mathrm{CO}_{2}$, concentration $\left(\mathrm{c}_{\mathrm{i}}\right)$ during drought and determination of minimum functional $C_{i}$. Plant Physiol. 111: 179-189.

Blum A (2016) Osmotic adjustment is a prime drought stress adaptive engine in support of plant production. Plant Cell Environ. 40: 4-10.

Cardona-Ayala CE, Jarma-Orozco A, Araméndiz-Tatis $H$. Perneth-Montaño M, Vergara-Córdoba, CA (2013) Gas exchange and mass distribution of the cowpea (Vigna unguiculata [L.] Walp.) under water deficit. Agron Colomb. 31(3): 288-296.

Delgadillo IP, Montenegro LC, Pinilla GA, Melgarejo LM (2017) Medición de la fluorescencia de la clorofila a en algas encapsuladas en alginato de calcio. Acta biol Colomb. 22(2): 199-208.

Fahad S, Bajwa AA, Nazir U, Anjum SA, Farooq A, Zohalb A, Huang J (2017) Crop Production under Drought and Heat Stress: Plant Responses and Management Options. Front Plant Sci. 8: 1147.

Franks PJ, Drake PL, Froend RH (2007) Anisohydric but isohydrodynamic: Seasonally constant plant water potential gradient explained by a stomatal control mechanism incorporating variable plant hydraulic conductance. Plant Cell Environ. 30(1): 19-30.

Freitas RMO, Dombroski JLD, Freitas FCL, Nogueira NW, Pinto JRS (2017) Physiological responses of cowpea under water stress and rewatering in no-tillage and conventional tillage systems. Rev Caatinga. 30 (3): 559-567.

Hall AE (2012) Phenotyping cowpeas for adaptation to drought. Front Physiol. 3: 155.

Ishiyaku MF, Aliyu H (2013) Field Evaluation of Cowpea Genotypes for Drought Tolerance and Striga Resistence in the Dry Savanna of the North-West Nigeria. International J Plant Breed Genet. 7(1): 47-56.

Jiménez-Suancha S, Alvarado O, Balaguera-López E (2015) Fluorescencia como indicador de estrés en Helianthus annuus L. Una revisión. Rev Colomb Cienc Hortic. 9 (1): 149160.
Jin R, Wang Y, Liu R, Gou J, Chan Z (2016) Physiological and metabolic changes of purslane (Portulaca oleracea L.) in response to drought, heat, and combined stresses. Front Plant Sci. 6:1123.

Kuhlgert S, Austic G, Zegarac R, Osei-Bonsu I, Hoh D, Chilvers MI, Roth MG, Bi K, TerAvest D, Weebadde P, Kramer DM (2016) MultispeQ Beta: a tool for large-scale plant phenotyping connected to the open PhotosynQ network. R Soc Open Sci. 3 (10): 160592.

Lawlor DW, Tezara W (2009) Causes of decreased photosynthetic rate and metabolic capacity in waterdeficient leaf cells: a critical evaluation of mechanisms and integration of processes. Ann Bot. 103 (4): 561-579.

Merwad A-RMA, Desoky E-SM, Radyc MM (2018) Response of water deficit-stressed Vigna unguiculata performances to silicon, proline or methionine foliar application. Sci. Hort. 228: 132-144.

Olajide AA, Ilori CO (2017) Genetic Variability, Performance and Yield Potentials of Ten Varieties of Cowpea (Vigna unguiculata (L) Walp) under Drought Stress. Legume Genomics Genet. 8 (3): 17-25.

Ovalesha MA, Yadav B, Rai PK (2017) Effects of polymer seed coating and seed treatment on plant growth, seed yield and quality of Cowpea (Vigna unguiculata). J Pharmacogn Phytochem. 6(4): 106-109.

Ping MA, Tuan-hui BAl, Feng-wang MA (2015) Effects of progressive drought on photosynthesis and partitioning of absorbed light in apple trees. J Integr Agric 14(4): 681-690.

Rincón-Suárez LF (2009) Curso básico de modelos lineales. Universidad Santo Tomás. Bogotá, Colombia. Departamento de publicaciones. $345 p$.

Rivas R, Falcão HM, Ribeiro RV, Machado EC, Pimentel C, Santos MG (2016) Drought tolerance in cowpea species is driven by less sensitivity of leaf gas exchange to water deficit and rapid recovery of photosynthesis after rehydration. $\mathrm{S}$ African J Bot. 103: 101-107.

SAS (Statistical Analysis System, US) (2008) SAS/STAT ${ }^{\circledR} 9.2$ User's Guide. Institute Inc. Cary, NC. USA. 889 p.

Sicher RC, Timlin D, Bailey B (2012) Responses of growth and primary metabolism of water stressed barley roots to rehydration. J Plant Physiol. 169: 686-695.

Singh SK, Reddy KR (2011) Regulation of photosynthesis, 898 fluorescence, stomatal conductance and water-use efficiency of cowpea (Vigna unguiculata [L.] Walp.) under drought. J Photochem Photobiol B, Biol. 105 (1): 40-50.

Surabhi GK, Reddy KR, Singh SK (2009) Photosynthesis, fluorescence, shoot biomass and seed weight responses of three cowpea (Vigna unguiculata (L.) Walp.) cultivars with contrasting sensitivity to UV-B radiation. Environ Exp Bot. 66: $160-171$.

Tardieu F, Simonneau T (1998) Variability among species of stomatal control under fluctuating soil water status and evaporative demand: modelling isohydric and anisohydric behaviours. J Exp Bot. 49: 419-432. 